\title{
DEL RECONOCIMIENTO LEGAL AL RECONOCIMIENTO EFECTIVO \\ DE LA IGUAL DIGNIDAD COMO UN DERECHO DE LA PERSONA CON DISCAPACIDAD INTELECTUAL O DEL DESARROLLO. UN PROCESO QUE NOS INTERPELA
}

\section{From Legal to Effective Recognition of Equal Dignity as a Right of the Individual with Intellectual and Developmental Disabilities. A Process that Challenges us}

\author{
Tatiana URIEN OrTIZ \\ Asociación Uribe Costa en Favor de Personas con Discapacidad Intelectual. C/ Amaia, 2, 2. ${ }^{\circ}$ G. \\ 48940 Leioa (Vizcaya) \\ tatiana.urien@hotmail.com
}

Recepción: 1 de diciembre de 2015

Fecha de aceptación definitiva: 14 de abril de 2016

Resumen: Este artículo analiza las implicaciones éticas que trae consigo reconocer la discapacidad como una cuestión de derechos humanos. La manera más difundida de comprender la discapacidad está inspirada en una estructura bienestarista que relega los deseos de la persona a las necesidades del colectivo. Esta nueva conceptualización, inspirada por influyentes filósofos como Dworkin y Margalit, entiende la dignidad como un derecho de la persona a que su vida se desarrolle en un contexto inclusivo generador de autorrespeto.

Palabras Clave: dignidad como capacidad; dignidad; autorrespeto; derechos humanos; egalization; discapacidad intelectual o del desarrollo; igualdad de oportunidades. 
AвSTRACT: This article analyzes the ethical implications of acknowledging disability as a human rights issue. The most common way to understand disability is inspired by a welfarist structure where collective needs trump the wishes of the individual. This new conceptualization, inspired by influential philosophers, such as Dworkin and Margalit, understands dignity as the individual's right to have their life unfold in an inclusive context that creates self-respect.

KEY WORDS: dignity as capacity; dignity; self-respect; human rights; egalization; intellectual or developmental disability; equal opportunities.

\section{Introducción}

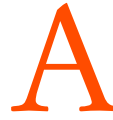

LO LARGO DEL TIEMPO EN LA SOCIEDAD OCCIDENTAL hemos estructurado el mundo conforme a dos criterios morales fundamentales: la religión, primero, y la capacidad que tiene el ser humano para razonar y generar recursos, después (De la Corte, Blanco y Sabucedo, 2004). Pero, tal y como vaticinó Ortega y Gasset, el gran reto de nuestro tiempo será ordenar el mundo desde el punto de vista de la vida -es decir, desde el derecho que tiene cualquier persona a tener una vida digna-. Elevando ésta a categoría de principio y convirtiéndola en fuente de derecho (Ortega y Gasset, 1988 citado en De la Corte et al., 2004: 13).

Esta observación orteguiana toma especialmente sentido para las personas con discapacidad intelectual o del desarrollo (DID) con la promulgación de la Convención Internacional sobre los Derechos de la Persona con Discapacidad (ONU, 2006), donde la comunidad internacional reconoce formalmente su derecho a que el mundo se ordene, también, desde el punto de vista de su vida en virtud de su igual dignidad.

Tomando el derecho a una vida digna como premisa fundamental para justificar la discapacidad como una cuestión de derechos humanos (Campoy Cervera, 2004; ONU, 2006; Palacios, 2009), el objetivo de este artículo será analizar el concepto de dignidad en relación a la persona con DID, no sólo como un valor moral inalienable, sino como un compromiso ético de transformación sistémica (Bronfenbrenner, 1987).

Con este propósito, comenzaremos situando en nuestro contexto social, psicológico y moral esta nueva manera de ordenar el mundo en la que la dignidad se convierte en fuente de derecho. Seguidamente analizaremos la evolución del concepto dignidad hasta llegar al concepto de dignidad plena de R. Dworkin (2003). Continuaremos examinando la posibilidad de dignidad plena en las personas con DID desde el paradigma funcional o asistencialista. Posteriormente, aportaremos algunas claves desde la ética igualitaria que justifiquen la importancia de considerar metodológicamente la dignidad como un valor intrínseco al individuo del que dimana, extrínsecamente, el derecho de todo ser humano a vivir en un entorno generador de autorrespeto. Dichas claves nos permitirán desarrollar el paradigma de los apoyos y los derechos, desde el marco interpretativo de la Convención Internacional sobre los Derechos de las Personas con Discapacidad (ONU, 2006). Y concluiremos con unas consideraciones que nos ayuden a avanzar en el camino hacia el reconocimiento en la vida cotidiana de la dignidad plena inherente a la persona con DID.

(C) Ediciones Universidad de Salamanca / CC BY-NC-ND

Siglo Cero, vol. 47 (2), n. ${ }^{\circ}$ 258, 2016, abril-junio, pp. 43-62 


\section{La igual dignidad: un desafío del s. XXI}

Las personas somos, en gran medida, lo que los otros consideran que somos, el modo en el que nos comprenden los otros. En la cultura occidental nos gusta creer que somos individuos autónomos con control sobre las decisiones que tomamos en nuestra vida. Pero la evidencia científica manifiesta que, muy al contrario, el ser humano orienta su comportamiento hacia los objetos en el mundo social según el significado que previamente les ha asignado. Por lo que es la manera en la que nos conceptualizan los otros la que nos configura (Appiah, 2007; Berger y Luckmann, 2012).

Por tanto, tal y como apuntan Palacios y Romañach (2009), el modo en el que la sociedad construye el constructo persona con discapacidad intelectual o del desarrollo tendrá extraordinarias consecuencias para la posibilidad de vida plena de la persona. Ya que, en función del imaginario desde el que se estructura la relación personaentorno, la persona puede ver conculcada o salvaguardada la igual dignidad inherente a cualquier ser humano en tanto humano.

Si mantenemos la premisa de que las personas somos, en gran medida, la situación en la que vivimos, el desarrollo conceptual de la igual dignidad parece que nos interpela como sociedad de manera fundamental. Supone tomar conciencia de la extraordinaria importancia moral de cuestionar los procesos e interacciones generadores de diferencias sistémicas en la dignidad intrínseca de las personas. Y nos conduce a plantearnos estrategias capaces de revertir aquellas situaciones esencialmente injustas entre los seres humanos, que atentan contra la dignidad universal y ponen en peligro su anhelo más básico: construir y controlar su proyecto de vida plena en un contexto de igual consideración.

Esta tensión respecto a las supuestas diferencias en la dignidad de las personas ha sido el gran debate moral del siglo pasado, y continuará siéndolo, con toda probabilidad, a lo largo del presente siglo. Si bien, no siempre ha sido así. Durante siglos se ha asumido con naturalidad la existencia de personas con más valor que otras.

Pero la Declaración Universal de los Derechos Humanos (ONU, 1948) supone el reconocimiento normativo de lo que será el espíritu de una nueva ética. Una ética donde impera el mensaje de la igual dignidad universal, donde todos los seres humanos somos iguales por derecho, en virtud de nuestra igual humanidad: "Considerando que la libertad, la justicia y la paz en el mundo tienen por base el reconocimiento de la dignidad intrínseca y de los derechos iguales e inalienables de todos los miembros de la familia humana” (ONU, 1948: Preámbulo).

Si bien este tránsito desde el reconocimiento legal de la igual dignidad inherente a todas las personas a su reconocimiento real en la vida cotidiana no es automático (Camino y Mendoza Pinto, 2004). El tránsito del deber ser al ser es un proceso paulatino, puesto que el reconocimiento de la igual dignidad, además de ser un valor moral inalienable, es un complejo proceso psicológico y social. Lindner (2006), poniendo en valor aquellos aspectos positivos que trae consigo la globalización -entendida ésta como la unión instantánea de la humanidad impulsada por la tecnología-, acuña el término egalization para definir este proceso psicosocial de reconocimiento mutuo 
de la igual dignidad de todos los seres humanos por el mero hecho de serlo, según lo especificado por los ideales de los derechos humanos.

Este proceso de egalization, de reconocimiento intersubjetivo de la igual dignidad descrito por Lindner (2006), como todo proceso psicológico y social, lejos de ser instantáneo, se hace efectivo de forma progresiva a través de la negociación entre los significados socioculturales predominantes y los nuevos significados que tratan de emerger (Berger y Luckmann, 2012; Camino y Mendoza Pinto, 2004) de acuerdo a esta nueva ética de la igual humanidad.

Parece, por tanto, que el reconocimiento formal del igual derecho que tiene todo ser humano a tener una vida digna por el mero hecho de serlo, que implica la Declaración Universal de los Derechos Humanos (ONU, 1948), más que ser un punto de llegada, se nos presenta como un punto de partida para la oportunidad de vida plena en la vida cotidiana de las personas con DID en tanto seres igualmente humanos.

Sin lugar a dudas, con este proceso de egalization (Lindner, 2006), nos enfrentamos, muy probablemente, a la gran utopía moral de nuestro tiempo. Extraordinario desafío que nos compromete éticamente de manera inapelable.

\section{La dignidad. Un concepto que evoluciona}

Partimos de la premisa casi tautológica de que todos los seres humanos, por el mero hecho de serlo, somos seres con igual dignidad. La dignidad es consustancial a la persona en virtud de su igual humanidad. Así el art. 1 de la Declaración Universal de los Derechos Humanos (ONU, 1948) señala: “Todos los seres humanos nacen libres e iguales en dignidad y derechos y, dotados como están de razón y sentido, deben comportarse fraternalmente los unos con los otros".

En este primer artículo (ONU, 1948) intuimos en su formulación, aunque no en el espíritu, un vestigio de la herencia de la tradición filosófica occidental. Tradición que ha entendido al ser humano como agente moral dotado de razón y sentido (Asís, 2009).

Analizar el concepto dignidad supone afrontar una de las tareas más complejas y controvertidas de la teoría moral, ya que implica abordar una de las cuestiones éticas que definen más radicalmente la esencia de lo humano.

Dignidad procede del latín dignitas, que significa honor social, honor extrínseco que implica una posición de prestigio o decoro, que merece (Margalit, 1997). Si bien esta noción inicial ha ido enriqueciendo su significado y alcance conforme han variado las respuestas que la sociedad occidental ha dado a la tradicional pregunta ¿qué es el hombre? Puesto que, sabiendo lo que el ser humano es, podremos tratarle como tal, como lo que se es, como merece. Es decir, dignamente.

De las distintas respuestas que a lo largo del tiempo hemos dado a esta controvertida y compleja cuestión sobre la naturaleza humana y, por ende, de los sucesivos significados que en el debate ético y político ha adquirido este complejo concepto, podríamos decir que la concepción kantiana de dignidad es la que ha ejercido un mayor influjo en nuestra tradición cultural. Kant entiende la vida humana con un valor intrínseco por el mero hecho de ser humana. Siendo la capacidad racional del ser 
humano quien fundamentalmente define nuestra humanidad y garantiza la posibilidad de nuestra autonomía moral. Desde esta posición, los seres humanos somos iguales porque compartimos con los otros seres humanos la cualidad de un absoluto valor intrínseco -entendido éste como conjunto de capacidades morales e intelectuales-, independientemente de las situaciones en las que se desarrolle nuestra vida.

De manera que la noción de dignidad humana predominante en nuestro pensamiento moral se ha construido a partir de una dimensión abstracta de la persona, dejando a un lado su dimensión situacional (Asís, 2009b). Produciéndose una identificación, sostiene Campoy Cervera (2014), entre las facultades racionales del ser humano y su propia esencia. Y es sobre esta noción de dignidad abstracta, basada en este modelo de individuo des-situado y caracterizado por su capacidad como agente moral, sobre la que se cimenta la teoría de los derechos humanos.

Si bien, este concepto de dignidad intrínseca que sirve como fundamento de los derechos humanos tiene dificultades a la hora de traducirse en un modelo político, ya que la dignidad intrínseca se refiere a un orden metafísico-ontológico, pero no contempla una dimensión político-práctica. Es decir, la dignidad intrínseca permite fundar los derechos, pero apenas dice algo sobre su cumplimiento efectivo, ya que no estamos ante la descripción de un hecho sino de un deber ser.

El constructivismo kantiano, abanderado por el teórico igualitarista Rawls, intenta salvar este importante escollo y trata de elaborar una teoría que suponga la manifestación práctica de la vivencia de la dignidad, implementando procedimientos a través de un algoritmo social, que nos lleven a desarrollar una vida digna tomando en cuenta esta dimensión contextual o situada que Kant ignora.

\section{Analizando el concepto de dignidad plena}

En línea con el planteamiento de Rawls, y con la intención de tomar en consideración esta dimensión político-práctica, intentaremos analizar la estructura profunda que subyace a esta noción moral tan compleja y fundamental como es el concepto de dignidad, guiándonos a través de las coordenadas propuestas por la teoría del individualismo ético del filósofo del derecho Ronald M. Dworkin, quien ejerció una importante influencia con Los Derechos en Serio (1984), tal y como apunta Rosales (2012), en la redacción de la Convención Internacional sobre los Derechos de las Personas con Discapacidad (ONU, 2006).

Para facilitar la comprensión del concepto de dignidad de Dworkin realizaremos una distinción metodológica (Palacios y Romañach, 2009) dentro de esta única noción moral fundamental, y distinguiremos una cara intrínseca o dignidad como valor y un cara extrínseca o dignidad como derecho, que dialécticamente relacionadas se concretan en dignidad como un único concepto moral.

Dworkin (2005 y 2008) entiende esta cara intrínseca o dignidad como valor como fruto de la articulación de dos actitudes morales fundamentales: el autorrespeto que emana de saber nuestra vida con igual valor que las otras vidas y la especial responsabilidad que sentimos sobre nuestra propia felicidad. Para este autor ambas actitudes 
son dimensiones o principios de condición de posibilidad de la dignidad -o, lo que es lo mismo, en su individualismo ético, de la vivencia de la dignidad-y, por ende, de llevar a cabo un proyecto de vida plena.

Es decir, con independencia del color de nuestra piel, nuestras preferencias sexuales o nuestras necesidades de apoyo para desenvolvernos en el entorno, debemos sentirnos igualmente considerados que el resto de los seres humanos ante nosotros mismos, ante los otros y ante la comunidad política. Se trata de que tengamos una actitud moral tal que, nos suceda lo que nos suceda y elijamos lo que elijamos en nuestra vida, nos consideremos y nos consideren como iguales al resto de los humanos. Puesto que todas las vidas son igualmente valiosas, ya que todas las vidas son igualmente humanas. No hay vidas que valgan más que otras (Dworkin, 2003).

La convicción de que mi vida tiene el mismo valor que las otras vidas, la certeza del igual valor de mi propia vida en comparación con la vida de otras personas despierta una actitud moral en cada uno de nosotros: el autorrespeto, la experiencia fundamental de pertenencia a la especie humana, a la familia humanidad (Dworkin, 2003 y 2008; Fernández Dols, 2004; Margalit, 1997).

Pero pese a que sabemos nuestra condición esencialmente obligada de humanidad, el autorrespeto se abre al diálogo con los otros (Margalit, 1997). La actitud de que mi vida es tan valiosa como la de los otros depende de manera importante de la actitud que tengan los otros hacia mí. Puesto que el respeto tiene su razón de ser en el hecho de reconocernos unos a otros como humanos. Y es, tal y como hemos anticipado, en ese reconocimiento de mutua humanidad donde se presenta la vivencia de la dignidad (Dworkin, 2003; Margalit, 1997).

Continuando con el análisis del concepto de dignidad plena, el otro valor moral que en la teoría dworkiana forma parte de la dignidad es la libertad. Libertad que se traduce en la actitud moral de especial responsabilidad sobre nuestra propia vida. Si hacemos un análisis introspectivo, nos daremos cuenta de que cada uno de nosotros se siente especialmente responsable para con su propia felicidad en comparación con la responsabilidad que siente para con la felicidad de los otros. Y es que, una vez que nuestra vida ha comenzado, debe ser una vida lo más plena posible, no debe desperdiciarse.

Es importante tener en cuenta, comenta Dworkin (2003 y 2008), que las elecciones que hagamos encaminadas a tener una vida lo más plena posible no son elecciones con valor ético. Tan sólo existe un imperativo: nadie puede forzarnos a elegir la vida que tenemos que llevar. Es indiferente desde el punto de vista moral que nuestro propósito de felicidad sea triunfar en el mundo de la canción o tener una vida dedicada a la cooperación al desarrollo. Lo moralmente importante es que experimentemos la actitud moral de especial responsabilidad, de hacernos cargo de la plenitud de nuestro proyecto vital. En caso contrario, si un tercero decide sobre nuestros deseos vitales, atentará directamente sobre nuestra dignidad, sobre lo que nos hace humanos.

Esta responsabilidad especial de cada persona sobre su propia vida, continúa, no puede quedarse en una dimensión meramente individual, sino que entra directamente en relación con el otro, ya que, si mi vida tiene igual valor que las otras vidas, mi proyecto de vida plena tiene igual valor que el proyecto de vida plena de los otros. 
En su argumentación Dworkin (2003 y 2008) no sólo entiende la dignidad como un valor intrínseco al individuo, sino que entiende que este valor moral fundamental tiene una cara extrínseca que dimana directamente de ambas dimensiones o principios de la dignidad: el derecho a ser tratado con una determinada actitud. Una actitud que exprese el reconocimiento de que toda persona es un ser humano cuya dignidad importa. Es decir, el reconocimiento del derecho a vivir en unas condiciones tales donde sea posible que los dos principios condición de posibilidad de una vida digna se hagan efectivos.

\section{La dignidad de la persona con DID: ¿̨una cuestión de capacidad?}

Si estrechamos el foco de nuestra mirada del ser humano en general al ser humano con DID, se nos presentan importantes interrogantes desde el punto de vista moral. Por ejemplo: ¿Percibe la persona con DID por parte de su entorno más cercano, de las organizaciones y de la comunidad política que su proyecto de vida es tan valioso como el proyecto de vida de los otros? ¿Se dan las condiciones mínimas para que la persona tenga la experiencia moral de hacerse cargo de su propia vida? En definitiva, ¿posibilitamos los diferentes niveles del sistema -micro, meso y macro-que la persona con DID se perciba a sí misma revestida de esa luminosidad existencial que supone saberse sujeto de igual dignidad?

La conceptualización de la persona con discapacidad es una cuestión compleja fuente de importantes discrepancias según el modelo ético y el contexto cultural dentro del cual se defina (Palacios y Romañach, 2009). Ya que en función del imaginario social desde el que se objetive el constructo persona con discapacidad intelectual o del desarrollo (Asís, 2013; Palacios y Bariff, 2007) se preservará o conculcará la posibilidad de vida digna de la persona con DID y, por lo tanto, su posibilidad de desplegar las actitudes moralmente fundamentales de autorrespeto y de control sobre su proyecto singular de felicidad (Dworkin, 2003 y 2008).

El paradigma asistencialista es la manera de conceptualizar a la persona con DID resultado de definir la dignidad desde un modelo de sujeto que se define por su capacidad. Se trata de una cosmovisión vigente todavía hoy en los ámbitos organizacional y social, aunque ya prácticamente superada en los ámbitos normativo y científico.

Este imaginario ha tenido un extraordinario impacto sistémico, que ha determinado las relaciones persona con DID-entorno y, por tanto, su posibilidad de una vida digna, en las últimas décadas (Palacios, 2008). La conceptualización de la persona con DID desde esta cosmovisión significó un gran avance en lo que a su consideración como ser humano se refiere. Ya no supone que la discapacidad tenga un origen religioso, sino que concibe la discapacidad como algo patológico que es mejor no tener, pero consecuencia de la mala suerte, no de un castigo divino (Palacios, 2008).

Dicha forma de definir a la persona con DID, por su propia mecánica interna comparativo-competitiva, convierte a la capacidad y, por tanto, a la inteligencia, en operadores políticos para graduar la dignidad de las personas (Tamburrino, 2009), lo que se traduce en una relación de poder asimétrica del entorno para con la persona con DID. 
Este modelo jerárquico de comprensión del ser humano, apuntan Palacios y Romañach (2009), entiende, todavía, que las personas que por su situación de discapacidad no pueden contribuir de manera efectiva a la comunidad no pueden ser consideradas sujetos causales de su propia vida. Es decir, entiende que, dada su incapacidad de hecho, es importante que la persona cuente con alguien, reconocido por derecho, con plenitud de capacidad que tome en su lugar las decisiones sobre su vida (Campoy Cervera, 2004).

Desde esta graduación capaz-incapaz, el Estado considera que quien debe ser compensada por tener en su seno una persona con una situación vital de discapacidad es la familia. Por lo que la norma jurídica coherente con este paradigma aborda la situación vital de DID prácticamente de manera exclusiva dentro de la legislación de la asistencia y seguridad social, o como parte de ciertas cuestiones del derecho civil relacionadas con la incapacitación y la tutela, y apenas nada desde la óptica de la autonomía y la capacidad (Asís, 2013).

Desde esta perspectiva se organiza una sociedad del como si. Una sociedad artificial paralela para personas con déficits donde puedan relacionarse entre ellas como si no tuvieran discapacidad. El como si se convierte en la clave de esta sociedad paralela habitada sólo por personas con DID. Así una persona puede vivir toda su vida como si viviera una vida de adulto, sin vivir una vida de adulto, trabajar en el centro ocupacional como si trabajase en la empresa ordinaria, percibir una gratificación por su trabajo en el centro como si fuese un sueldo, etc.

En este engranaje paternalista los deseos de la persona quedan relegados a lo que el sistema decide que le conviene en virtud de sus necesidades (Tamarit, 2010). Prácticamente las únicas señas de identidad que reconoce la sociedad a las personas con DID son los indicadores de necesidad social, y no ninguna otra característica que la propia persona pueda identificar como propia.

Así es posible que la administración le asigne una vivienda en función de su perfil de apoyo, sin preocuparse de lo cerca o lejos que vive su red de apoyo natural, o le asigne un centro ocupacional que mejor conviene a la ruta de transporte, y no en función de si las actividades ocupacionales que allí se desarrollan coinciden con sus intereses y vocación. Desde este imaginario, ¿se contempla, tan siquiera, que la persona con DID puede tener vocación?

Este paradigma bienestarista considera falazmente que, por el mero hecho de que los servicios sean de calidad, el bienestar de las personas aumenta y, por ende, las personas son más felices (Schalock y Verdugo, 2013). Es decir, se considera que si ofrecemos a las personas servicios bien estructurados, sistematizados, procedimentados y organizados que optimicen sus resultados funcionales, mejoren su conducta adaptativa y velen por sus necesidades básicas, su salud y su seguridad, estaremos haciendo bien nuestro trabajo de mejorar las vidas de las personas, y las personas serán felices.

Se ha conceptualizado al colectivo de personas con DID como un colectivo que tiene tantas y tan importantes necesidades que no tiene lugar para anhelos singulares de felicidad (Tamarit, 2010). Hemos realizado desde este imaginario una identificación colectiva de lo que significa tener bienestar, ser feliz. Se considera que es a la sociedad a quien le corresponde el deber de dar una respuesta de calidad a estas enormes 
carencias que presentan como grupo, derivadas de tener una deficiencia. La individualidad de la persona y su libertad para decidir su proyecto singular de felicidad desaparece ante las necesidades propias del colectivo (Tamarit, 2010).

¿Hemos caído en la tentación de creernos hadas madrinas con el poder de insuflar felicidad y bienestar a las personas a través de esta sociedad de fantasía modulada desde la que terceros con capacidad consideramos que proporciona felicidad a las personas, por el mero hecho de tener una situación de DID? ¿Dónde queda la individualidad de cada persona, sus deseos, sueños y potencialidades? Este criterio bienestarista de asignación de prestaciones y apoyos ¿permite llegar al anhelo de cada persona, a la esencia de lo que le hace al ser humano ser humano?

\section{Construyendo entornos generadores de autorrespeto: la dignidad como derecho}

En coherencia con el mensaje igualitario de la dignidad plena, tal y como sostiene Dworkin (2003), parece inevitable dar un giro copernicano en la manera de conceptualizar el constructo persona con discapacidad intelectual o del desarrollo. Y descentrarnos de las disposiciones internas de la persona, para centrarnos en la construcción de un nuevo imaginario social que avance en el proceso egalization, es decir, de desarrollo efectivo de la igual dignidad de la persona con DID por el mero hecho de ser persona (Lindner, 2006; ONU, 2006) modulado por las condiciones situacionales en las que la persona con DID desarrolla su vida.

La verdadera transformación efectiva hacia una manera de conceptualizar a la persona con DID desde el paradigma de la dignidad plena, apunta De Lorenzo (2003), radica en que la sociedad civil tome conciencia no sólo desde el punto de vista racional, sino también desde el plano emocional, de lo injusta de esta situación: de que para que la mayoría pueda tener una vida plena elegida, otros no puedan desarrollar un proyecto vital significativo. Ya que todos los planes de vida son igualmente valiosos, no se trata de garantizar que todos tengan una vida plena preferida, sino de que todos tengan la oportunidad de disfrutar de una vida plena elegida, en virtud de su igual dignidad, mantienen Dworkin (2003) y Rawls (1979).

Ambos autores sostienen que sólo será lícito que se produzcan desigualdades (sociales, económicas, etc.) entre las personas si tales diferencias producen beneficios que compensen a los que están en peor situación. Así, esta ética igualitaria consideraría lícito recortar la partida presupuestaria para ordenadores personales para la población escolar, si dicha acción supusiera el aumento del importe de ayudas para el apoyo a la inclusión educativa a niños con DID.

Es responsabilidad de la comunidad, sostiene Dworkin (2003 y 2008), el velar por que estos recursos se empleen de forma justa. Incluyendo en esta idea de justicia el establecimiento de una política redistributiva que tienda a compensar las diferencias relacionadas con los recursos personales de cada individuo -personas con alguna discapacidad o de los que no tienen la capacidad necesaria para obtener unos ingresos satisfactorios-.

La condición de posibilidad de esa cara extrínseca de la dignidad entendida como el derecho a la igual consideración y respeto que plantea Dworkin (2003) hunde sus 
raíces en un nuevo modelo sociopolítico que haga posible que ordenemos el mundo, parafraseando a Ortega y Gasset (1988), desde el punto de vista de la vida de la persona con DID, de manera que ésta pueda disfrutar de una vida digna elegida.

Estamos ante un planteamiento que va mucho más allá de la libertad individual, ya que, además de querer ser libres como individuos, debemos elegir comunitariamente una forma de vida que sea coherente y haga posible una libertad igual para todos, con un reparto igualitario de los recursos necesarios para que cada ciudadano pueda llevar a cabo la vida que desea vivir, dentro lo posible con los recursos que tiene (Camps, 1997).

La clave de esta cara extrínseca de la dignidad (Palacios y Romeñach, 2009) está en el concepto de igualdad de oportunidades (Dworkin, 2003, 2008). Igualdad de todos en la oportunidad para ser libres, para autodeterminarnos, para escoger la vida que queremos vivir. La igualdad de oportunidades no sólo exige una actitud ética sobre la igual motivación de la comunidad política hacia todos sus ciudadanos, sino que también es preciso un Estado interventor que se encargue de evitar las injusticias derivadas de un reparto desigual de aquellos recursos que se consideran fundamentales para poder ser libre.

Tenemos el deber, continúa Dworkin (2003), de llegar a un acuerdo y tejer un modelo de comunidad que permita estrategias redistributivas compensatorias para reparar en la medida de lo posible las desigualdades en las capacidades personales y la mala suerte -discapacidades, enfermedades, catástrofes naturales, etc.-, provocando la creación de redes generadoras de autorrespeto.

Parece, por tanto, que la moral pública tiene que sustentarse en algo más que el deseo de libertad. Debemos construir una noción común de justicia y solidaridad que posibilite la vida digna de todos los seres humanos, de manera que cuenten con los recursos suficientes para llevar a cabo su proyecto de vida plena elegida en un contexto de igualdad de oportunidades (Dworkin, 2003).

Hacia un paradigma horizonte de la dignidad plena de la persona con DID: el paradigma de los derechos y los apoyos

Pero, ¿qué sucede con la dignidad de las personas con DID? Aun en el caso utópico de que se hiciera realidad este modelo social igualitario, una distribución equitativa de recursos (sociales, materiales, económicos, etc.) ¿sería suficiente para que la persona con DID se sienta respetada en la vida cotidiana en su dignidad plena inherente? Es decir, una distribución equitativa de recursos ¿es garantía suficiente para que se respete el honor intrínseco inherente a la persona con DID en virtud de su igual humanidad?

Disponer del asistente personal que le corresponde por derecho, para que le ofrezca el apoyo que necesite para desarrollar su vida en igualdad de condiciones que el resto de personas, ¿ es suficiente para que la persona con DID se sienta sujeto de dignidad plena? ¿O será igualmente relevante para su consideración como sujeto de dignidad plena la manera en la que le son ofrecidos los apoyos? Es decir, ¿ será lo mismo que se le ofrezcan los apoyos desde una relación de poder capaz-incapaz que desde una relación 
de igualdad persona-persona? Ambas maneras de recibir los apoyos ¿le permitirán desarrollar una actitud moral de autorrespeto y de control sobre su propia vida?

Al hilo de cuestiones de esta índole, Margalit (1997) matiza que el planeamiento de una sociedad donde triunfe la justicia social (Dworkin, 2003; Rawls, 1979) es un planteamiento moralmente necesario, dado que nos indica un ideal desde el que organizar la estructura básica de la sociedad, pero no suficiente. Puesto que una distribución de recursos igualitaria no implica que el procedimiento en la distribución también lo sea (Fernández Dols, 2004). Así puede ser que el Estado cumpla con su obligación de ofrecer una vivienda con apoyo a las personas con DID que así lo deseen, pero no les dé la oportunidad de sentir que están en su propia casa (participando en la selección de los apoyos, teniendo sus propios muebles, respetando su intimidad, etc.).

Es importante, asevera Margalit (1997), que, teniendo en el horizonte la igual distribución de bienes y libertades entre todos los seres humanos por el mero hecho de serlo (Dworkin, 2003; Rawls, 2006), nos planteemos como meta en la vida cotidiana lo que este autor denomina la sociedad decente. Es decir, una sociedad donde, a través de las respuestas psicológico-morales de respeto y simpatía (Glover, 2001), se genere una relación persona-sistema que permita que emerjan en la persona con DID las actitudes morales de autorrespeto y control de la propia vida (Dworkin, 2003). De modo que una sociedad decente construirá una sociedad con unas instituciones tales que potenciarán el que la persona con DID se perciba como sujeto capaz de vivir, con los apoyos adecuados, la vida que desea vivir en un contexto de igual consideración (Dworkin, 2003; Margalit, 1997; Rawls, 2006).

En la línea de lo expuesto por Margalit (1997), Dworkin (2003) considera que el factor fundamental para avanzar hacia este contexto social generador de autorrespeto radica en dejar constancia legal de la necesidad moral del reconocimiento de la igual consideración y respeto a cualquier individuo humano, por el hecho de ser tal. Es decir, Dworkin (2003) considera imprescindible el reconocimiento legal de la obligación moral de respetar, reconocer y proteger la igual libertad de la persona con DID para diseñar sus propios planes de vida y controlar la realización efectiva de éstos.

\section{El reconocimiento legal de la igual dignidad de la persona con DID: un valor $y$ un derecho}

Esta exhortación dworkiana sobre el reconocimiento legal de la igual dignidad de la persona con DID en tanto igual miembro de la familia humanidad se hizo realidad el 13 de diciembre de 2006. Ese día en la ciudad estadounidense de Nueva York la Asamblea General de la ONU aprobó la Convención Internacional sobre los Derechos de las Personas con Discapacidad (Convención).

La Convención (ONU, 2006) fue ratificada por el Estado español el 21 de abril de 2008. Y desde el momento de la firma, su contenido es ley en nuestro país. Forzando a adaptar las normas jurídicas al contexto específico de discapacidad y estableciendo los mecanismos necesarios para garantizar el ejercicio de sus derechos, sin discriminación 
y en igualdad de oportunidades que el resto de las personas (Asís, 2013; Palacios y Bariffi, 2007).

Este tratado internacional (ONU, 2006) no debe entenderse como un tratado de derechos especiales para personas especiales por vivir con una situación de discapacidad (Asís, 2013; Palacios y Romañach, 2009), sino como una consecuencia lógica del proceso de generalización de los derechos a todas las personas (Dworkin, 2003; Rawls, 2006) que el proceso de egalization -igualdad universal- conlleva (Lindner, 2006). Así, en su artículo 1 enuncia, precisamente, como su propósito principal: “promover, proteger y asegurar el goce pleno y en condiciones de igualdad de todos los derechos humanos y libertades fundamentales por todas las personas con discapacidad y promover el respeto a su dignidad inherente" (ONU, 2006).

Dado el momento de reconocimiento de la igual dignidad de las personas con discapacidad en el que se aprueba la Convención (ONU, 2006), sus redactores consideraron necesario llamar la atención sobre la posible amenaza de que las personas con DID con una intensidad de apoyo extensa o generalizada corrieran el riesgo de continuar sin ser sujetos protagonistas de la construcción de un proyecto de vida elegido. Y, por tanto, sin ser sujetos de dignidad plena (Dworkin, 2003). Con ánimo de prevenir esta probable situación el artículo j del Preámbulo matiza: "La necesidad de promover y proteger los derechos humanos de todas las personas con discapacidad, incluidas aquellas que necesitan un apoyo más intenso” (ONU, 2006).

Además del reconocimiento legal del derecho de todas las personas con discapacidad, sea cual sea la intensidad de apoyo que la persona requiera para desenvolverse en el entorno, para elegir y controlar su vida, este marco interpretativo (ONU, 2006) asume el reconocimiento formal de la discapacidad desde un modelo ecológico. Es decir, la Convención (ONU, 2006), y con ella todos los países adheridos, asumen la definición de persona con discapacidad intelectual de Luckasson et al. (2002) que asume la AAIDD (2011). Donde la discapacidad ya no se entiende sólo como una disposición intrínseca de la persona, sino como el desajuste entre las capacidades de la persona y el contexto en el que ésta desarrolla su vida, debido a la injusta no adecuación de este contexto. Y no, sólo, como una condición interna de la persona.

Será la comunidad, por tanto, quien deberá hacer las adaptaciones necesarias para que la persona pueda desarrollar una identidad unificada y socialmente valorada (Erikson, 2000) y le permita disfrutar de las actitudes morales de autorrespeto y de control sobre la propia vida (Dworkin, 2003). Así, desde el paradigma asistencialista, que estamos éticamente comprometidos a abandonar, interpretaríamos que Luis, una persona con DI con una dificultad de comprensión lectora importante, no comprende lo que lee porque tiene una discapacidad causada por su deficiencia. Mientras que desde esta cosmovisión horizonte basada en derechos y apoyos entenderemos que debemos ser nosotros, su entorno, quienes tenemos el deber de adaptar los textos a Lectura Fácil, de manera que su deficiencia para la lectura comprensiva no le dificulte su derecho a acceder a la información y a la cultura escrita.

Este cambio en el foco de atención de las disposiciones internas del individuo a las circunstancias situacionales es un cambio especialmente dificultoso para los individuos de la sociedad occidental, ya que, mediante lo que se denomina el error 
fundamental de atribución, tendemos a interpretar el mundo desde las características internas del sujeto y, muy difícilmente, desde las situaciones en las que se desarrolla su vida.

Dada la importancia de las condiciones de vida para que la persona con DID tenga la oportunidad de desplegar su proyecto singular de felicidad, parece irrenunciable la adopción de un compromiso sistémico (Bronfembrenner, 1987) que asuma la esencial igual humanidad de la persona con DID. De modo que la elección de su proyecto vital no esté condicionada ni por las necesidades de apoyo ni por la rigidez de las estructuras organizacionales y comunitarias (AIDD, 2011; Shalock y Verdugo, 2013). De lo contrario, tal y como sostiene la Convención (ONU, 2006) en su artículo 2 incurriremos en una situación de discriminación por razón de discapacidad:

Cualquier distinción, exclusión o restricción por motivos de discapacidad que tenga el propósito o el efecto de obstaculizar o dejar sin efecto el reconocimiento, goce, en igualdad de condiciones, de todos los derechos humanos y libertades fundamentales en los ámbitos político económico, social, cultural, civil o de otro tipo.

Es decir, debemos incidir, especialmente, sobre aquellas condiciones del entorno que hagan posible que la dignidad como derecho (Asís, 2013; Palacios y Romañach, 2009) se haga efectiva. De manera que la persona con DID tenga la oportunidad en la vida cotidiana de ser libre de llevar la vida que desea llevar dentro de lo razonable, puesto que la comunidad política tiene la obligación de posibilitar que esta realización de la mejor vida posible sea efectiva (Dworkin, 2003; ONU, 2006).

En coherencia con esta tesis de Dworkin (2003) este paradigma horizonte basado en derechos y apoyos abandona la sociedad del como si, sociedad ficticia de centros y servicios donde las personas con discapacidad viven como si no tuvieran discapacidad. Para avanzar hacia una sociedad inclusiva que genere unas estructuras de apoyo donde las personas con DID sean consideradas ciudadanos con igual derecho a que sean respetadas sus ideas, a disfrutar de los recursos necesarios para acceder al entorno físico, al transporte, a la información, a la comunicación accesible y, por supuesto, al apoyo personal necesario para facilitar su existencia y su inclusión plena en la comunidad (ONU, 2006). En definitiva, para llevar a cabo una vida plena elegida en igualdad de condiciones respecto a todos los demás en un contexto de igual consideración.

Así el art. 19 de la Convención (ONU, 2006) reconoce legalmente este derecho de las personas con discapacidad a vivir la vida que desean vivir más allá de las instituciones específicas destinadas al efecto. Es decir, este artículo reconoce formalmente el derecho a que se activen de manera sistémica los dispositivos de apoyo necesarios para que las personas con DID tengan la oportunidad de disfrutar de las condiciones situacionales mínimas que le permitan elegir dónde y con quién vivir en un contexto inclusivo generador de autorrespeto dentro de su entorno natural.

En coherencia con este art. 19 (ONU, 2006), para que las personas con discapacidad tengan las mismas oportunidades, esto es, los mismos recursos que el resto de la población para llevar a cabo su proyecto de vida digna, parece necesario, tal y como apunta Dworkin (2003), que nos replanteemos el modelo de sociedad, hacia una forma de vida que sea coherente y haga posible esa libertad igual para todos. De forma

(C) Ediciones Universidad de Salamanca / CC BY-NC-ND

Siglo Cero, vol. 47 (2), n. ${ }^{\circ}$ 258, 2016, abril-junio, pp. 43-62 
que las personas podamos igualarnos en recursos que nos den la oportunidad de ser libres para vivir la vida que deseamos vivir dentro de lo razonable, con los recursos necesarios para participar en la sociedad de mercado en la que vivimos y llevar a cabo nuestra vida con unas mínimas garantías de plenitud.

En definitiva, la clave para que la persona con DID pueda disfrutar de un proyecto vital significativo está en el hecho de que su vida se desarrolle en un contexto de igual consideración, entendido éste como igualdad de oportunidades para ser libre. Igualdad de oportunidades que se traduce en igualdad de recursos para llevar a cabo una vida plena (Dworkin, 2003).

\section{Un contexto de oportunidad: el reconocimiento formal de la autonomía moral de la persona con DID}

La transformación de la mirada que persigue esta cosmovisión horizonte hacia la que nos dirigimos reconoce formalmente autonomía moral a la persona con DID. Entendiendo autonomía como capacidad de acción y comportamiento autodirigido (Palacios y Bariff, 2007: 78), en virtud de su igual dignidad.

Considerar la discapacidad como una cuestión de derechos humanos significa una transformación conceptual y normativa con revolucionarias implicaciones para la práctica cotidiana. Supone dejar de considerar el apoyo a la persona como una obligación social para con la persona y su familia para ser considerado como un derecho de la persona con DID a ser tratada con igual consideración y respeto por el mero hecho de ser humano. Implica, por tanto, una apuesta radical por el autorrespeto resultado de un imaginario que considera a la persona con DID como sujeto moral con derecho a unas condiciones situacionales tales que preserven y potencien su autonomía moral, tal y como le corresponde en virtud de su igual humanidad (Dworkin, 2003; Margalit, 1997).

El concepto de autonomía es un concepto que encierra gran complejidad. Especialmente si hablamos de la autonomía de la persona con DID. Cuando utilizamos el término autonomía referido a las personas con DID desde el paradigma asistencialista, solemos referirnos a cuestiones propias de la autonomía personal y social del individuo (comer solo, vestirse, autorregularse, iniciar conversaciones, enfrentar situaciones nuevas, etc.). E inferimos, mediante un sesgo cognitivo, que esta persona no tiene capacidad de acción como sujeto causal, sino que se trata de un sujeto heterónomo que debe ser, por su situación de discapacidad, objeto de la acción moral de un tercero. De este atajo mental resulta esta confusión entre necesitar apoyo para realizar una tarea -sujeto efectivo- y la capacidad de decisión para realizar esa tarea -sujeto causal- (Palacios y Romañach, 2009).

Así, pensemos en Marta, una persona con DI que en su vida diaria necesita apoyo para vestirse y autorregularse. Es probable que las personas que le prestamos apoyo infiramos, de manera falaz, que por necesitar apoyo en algunos aspectos de su vida no puede tener autonomía moral para decidir si le gustaría más ducharse antes o después de cenar, tener una estética heavy o surfer, tener el pelo largo o corto, 
etc. O decidir sobre aspectos de aparentemente más trascendencia vital, como vivir con sus padres o en una vivienda con apoyo permanente con su pareja, participar en pie de igualdad con su familia en las conversaciones sobre el futuro, elegir su ocupación, etc.

En coherencia con el espíritu de la Convención (ONU, 2006) debemos entender la autonomía de las personas con DID desde una concepción de agente causal moralmente libre (Dworkin, 2003). Y ésta es precisamente la función de los derechos: permitir que el sujeto con DID alcance esta libertad moral (Asís, 2013).

Sen (1997) contribuye a la reconceptualización de este concepto, sobre todo, en aquellas personas con DID con grandes dificultades en su funcionamiento intelectual, cuya autonomía se encuentra muy restringida. Para ello distingue entre poder efectivo y control. Las personas necesitamos tener poder para decidir sobre las cosas de nuestra vida, independientemente de si llevamos a cabo nosotros las acciones o no. El poder efectivo permite la elección contrafáctica. Esta elección es clave para el tema que nos ocupa, ya que supone ponerse en sus zapatos. Es decir, en el caso de que no podamos acceder a lo que la persona elegiría en una determinada situación, debido a la intensidad del apoyo que necesita, debemos decidir desde el más escrupuloso respeto a sus gustos y preferencias, y no conforme a lo que nosotros elegiríamos si fuera para nosotros. Es decir, debemos decidir en razón de la situación en cuestión, y nunca, en razón de la discapacidad (Asís, 2009b).

El interés superior propio del paradigma asistencialista debe ser sustituido por la mejor interpretación posible de su voluntad y preferencias (ONU, 2014: Disposición 20). Sólo así salvaremos la libertad que le corresponde a la persona con DID en virtud de su dignidad inherente (ONU, 2006).

Para que la autonomía moral sea efectiva no sólo es necesaria la libertad como valor, sino que es imprescindible, como sugiere Margalit (1997), un contexto de oportunidad. Esa oportunidad no significa otra cosa que confianza social. Confianza de los otros en la posibilidad de que las personas con DID tienen capacidad, con la intensidad de apoyo que cada persona precise, para elegir una vida significativa que otorgue sentido a su existencia.

Este tomarnos en serio los deseos de la persona con DID y generar estructuras de apoyo para que esta vida deseada se convierta en una vida disfrutada en la realidad de la vida cotidiana (ONU, 2006) significa avanzar un paso de gigante en la construcción social de este imaginario horizonte inclusivo, al que nos conduce el proceso de egalization-igualdad universal- en el que nos encontrarnos inmersos (Lindner, 2006).

Supone comprometernos como sociedad con su autonomía moral en virtud de su igual dignidad. Así todos hemos escuchado conversaciones, propias del imaginario asistencialista que intentamos abandonar, que denotan una clara minusvaloración de los gustos y preferencias de la persona con DID para construir su proyecto vital: "No te preocupes porque María diga que quiere vivir cerca de sus hermanos y de sus amigos. En la residencia que le asigne la Administración estará muy bien atendida. La experiencia nos dice que se acostumbran enseguida”. Como si lo que considera María significativo en su vida, por el hecho de tener una situación vital de DID, tuviera menos valor que lo que los otros consideramos valioso en nuestra 
vida. Esta minusvaloración del valor de la vida de la persona con DID ha llevado probablemente a que las condiciones que las personas con DID necesitan para tener control sobre sus vidas hayan sido históricamente ignoradas (De Lorenzo, 2003; Palacios y Bariff, 2007) y, por tanto, su igual dignidad, vulnerada.

De manera que otra de las claves de transformación del imaginario desde el que se conceptualiza el constructo persona con discapacidad intelectual o del desarrollo es que la intensidad de las necesidades de apoyo no podrá nunca servir para que una persona sea declarada objeto de la acción de un sujeto moral ajeno a sí mismo, en virtud de su dignidad plena, tal y como recoge el art. 12 de la Convención (ONU, 2006).

Este artículo implica un salto cualitativo de gran relevancia ética, normativa y simbólica, puesto que reconoce legalmente a la persona con DID como sujeto moral. El reconocimiento formal de la igual capacidad jurídica (capacidad para ser titular de derechos y deberes) de todas las personas, incluidas las personas con DID (ONU, 2006), es uno de los ejes vertebradores de este cambio de cosmovisión. Estamos ante un cambio fundamental a la hora de regular la capacidad legal de las personas con discapacidad. Especialmente, en aquellos casos en los que la persona tiene grandes dificultades a la hora de tomar decisiones propias, ya que propone un sistema de apoyo a la autonomía.

Es decir, en lugar de las habituales incapacidades totales permanentes propias del paradigma asistencialista, el art. 12 (ONU, 2006) establece articular modificaciones en la capacidad de obrar (capacidad efectiva para el ejercicio de derechos y deberes) para prevenir los abusos, respetando siempre los derechos y preferencia de la persona, diseñadas a la medida de la situación de cada persona, por el espacio de tiempo más corto posible y sujetas a exámenes periódicos por un órgano judicial competente (Asís, 2013; Palacios y Romañach, 2009). Estos dispositivos de apoyo a la toma de decisiones deben, asimismo, proteger contra la influencia indebida y respetar el derecho de la persona a asumir riesgos y a cometer errores (ONU, 2014: Disposición 22).

De manera que la Convención (ONU, 2006) supone el reconocimiento formal de este cambio de paradigma. Paradigma desde el que se reconoce a la persona con DID su condición de sujeto causal de su propia vida. Asumiendo que la detección de que una persona presenta una intensidad de apoyo determinada no deberá ser razón suficiente para que no tenga la oportunidad de participar en pie de igualdad en los asuntos que le conciernen, sino que significará que tendremos que ser capaces de darle el mejor apoyo disponible para que pueda hacerse cargo con el mayor éxito posible de la cuestión (AAIDD, 2011; ONU, 2014).

En definitiva, con la reconceptualización del concepto autonomía como autonomía moral, se vertebra la transformación de la estructura profunda del constructo persona con discapacidad intelectual o del desarrollo. Esto es, de ser humano de segunda clase no capaz y heterónomo (Margalit, 1997) que necesita que se le sustituya en la toma de decisiones al no poder razonar al mismo nivel que la media, al reconocimiento legal de su capacidad jurídica inherente independientemente de que pueda necesitar apoyo y ajustes razonables para el ejercicio de sus derechos y deberes, pero siendo siempre sujeto causal de las decisiones que le afectan (ONU, 2006).

Sin duda, el reto que tenemos por delante es mayúsculo. Necesitamos una sintaxis persona con DID-sistema (micro-meso-macro) y sistema-persona con DID 
(Bronfenbrenner, 1987) que nos permita transformar la estructura profunda del constructo persona con discapacidad intelectual o del desarrollo.

Nos encontramos, por tanto, ante una nueva manera de conceptualizar a la persona con DID (Asís, 2013) que radica en un respeto fundamental a la persona desde el reconocimiento esencial de su capacidad y autonomía, partiendo de su libertad radical y de su igual humanidad (ONU, 2006). Se trata de un encuentro del tú con el yo para hacer un nosotros. Un encuentro con el corazón de la persona, desde lo que nos une, poniendo en valor su diversidad, ya que humanidad = diversidad. Y desde ese encuentro esencial con nuestra consanguineidad psicológica y moral (Glover, 2001; Margalit, 1997), asumir un compromiso sistémico (Bronfenbrenner, 1987) con lo que cada persona con DID considera significativo en su vida, ya que la vida elegida es la vida de calidad (Dworkin, 2003).

\section{Consideraciones finales}

Parece probable que, si compartiéramos con nuestro entorno cercano la pregunta de si la persona con DID tiene derecho a una vida digna, seguramente la totalidad de los interrogados responderían que sí de manera contundente. Pero si reformuláramos la cuestión en términos más precisos (por ejemplo: ¿es la persona con DID una persona que necesita que alguien tome decisiones en su nombre y decida por ella la vida que quiere vivir?) probablemente la mayoría de las personas nos contestarían que también estamos en lo cierto.

¿Qué entendemos, entonces, por vida digna cuando nos referimos a una persona con DID? ¿Protegerle de las demandas de la vida? ¿O darle el apoyo que necesita para que pueda enfrentarse en igualdad de condiciones que las personas sin DID a lo que la vida le va pidiendo?

Aun a pesar del extraordinario valor de la Convención (ONU, 2006) para avanzar en el proceso de egalization-igualdad universal-(Lindner, 2006), el Comité sobre los Derechos de las Personas por Discapacidad -órgano independiente compuesto por expertos que tienen como misión supervisar la aplicación de este tratado internacional en los diferentes Estados Partes- sostiene en su último informe sobre el Estado español: "Aún no se ha comprendido que el modelo de la discapacidad basado en derechos humanos implica pasar del paradigma de la adopción de decisiones sustitutiva a otro que se base en el apoyo para tomarlas" (ONU, 2014).

Tomando en consideración esta observación del Comité sobre los Derechos de las Personas con Discapacidad (ONU, 2014), ¿qué factores impiden que la Convención se convierta en un marco interpretativo y en un código de conducta que determine en la vida cotidiana la interacción persona con DID-sistema? ¿Cuáles son los principales obstáculos que actualmente dificultan o imposibilitan la transformación de esa moral pensada en una auténtica moral vivida?

Si la Convención (ONU, 2006) tiene rango de ley en los países adheridos (Asís, 2009), ¿por qué los derechos vinculados a la Convención son conculcados o no suficientemente protegidos por las instituciones? ¿Es posible impulsar el reconocimiento 
jurídico y estimular la promoción política de los principios morales de la Convención sin una previa identificación intrínseca con dicho código ético?

Para que interioricemos el mensaje igualitario que emana de este tratado (ONU, 2006) ¿será suficiente con un organismo regulador internacional que vigile su cumplimiento? Es decir, para salvaguardar la dignidad inherente a la persona con DID ¿bastará con que se cumplan los deberes jurídicamente reconocibles vinculados a la Convención por miedo a una sanción o recriminación externa? ¿ $\mathrm{O}$ será imprescindible una identificación psicológico-moral con los valores que la legitiman?

En definitiva, ¿es posible ordenar el mundo desde el punto de vista de la vida de las personas con DID sin un compromiso intrínseco persona-persona con su igual humanidad?

Éstos son sólo algunos de los interrogantes que se nos presentan ante la enorme complejidad práctica que se nos aparece para con el reconocimiento de la discapacidad como una cuestión de derechos humanos.

Si bien el compromiso ético que nos interpela es contundente:

Tiene sentido tener derechos si su amenaza es vista como algo grave e importante. No verlo así en relación a un sujeto significaría tratar a un hombre como algo menos que un hombre como menos digno de consideración y respeto que otros hombres (Margalit, 1997: 40).

\section{Referencias bibliográficas}

AAIDD (2011). Discapacidad Intelectual (11. ${ }^{\mathrm{a}}$ ed.). Madrid: Alianza Editorial.

Appiah, K. A. (2007). Ética de la identidad. Buenos Aires: Katz Ed.

Asís, R. de (2009a). Presentación. En A. Palacios y J. Romeñach, El modelo de la diversidad. Madrid: Ediciones Diversitas.

Asís, R. de (2009b). Sobre la capacidad. Papeles el Tiempo de los Derechos, 4, 1-7. En www. tiempodelosderechos.es/biblioteca/doc.../5-sobre-la-capacidad.html.

Asís, R. de (2013). Concepción de la discapacidad en el modelo social. Críticas y éxitos. Papeles el Tiempo de los Derechos, 1, 1-14. En http://e-archivo.uc3m.es/bitstream/handle/10016/19304/modelo_asis_PTD_2013.pdf?sequence=1.

Berger, P. y Luckmann, T. (2012). La construcción social de la realidad. Madrid: Amorrortu Editores.

Bronfenbrenner, U. (1987). La ecología del desarrollo bumano. Experimentos en entornos naturales diseñados. Barcelona: Paidós.

Camino, L. y Mendoza, R. (2004). La construcción de los derechos humanos y la necesidad de la psicología política. Psicología Política, 28, 85-103. En http://www.uv.es/garzon/psicologia\%20politica/N28-5.pdf.

Campoy, I. (2004). Una revisión de la idea de dignidad humana y de los valores de libertad, igualdad y solidaridad en relación con la fundamentación de los derechos. Anuario de Filosofía del Derecho, 21, 143-166. En e-archivo.uc3m.es/bitstream/handle/.../revision_campoy_AFD_2004.pdf...

CAmps, V. (1997). La igualdad de oportunidades en la filosofía actual. Revista de Intervención Psicosocial, vol. 6 (1). En www.copmadrid.org/webcopm/publicaciones/social/1997/ .../arti2.htm. 
DEL RECONOCIMIENTO LEGAL AL RECONOCIMIENTO EFECTIVO DE LA IGUAL DIGNIDAD COMO UN DERECHO DE LA PERSONA CON DISCAPACIDAD INTELECTUAL O DEL DESARROLLO. UN PROCESO QUE NOS INTERPELA TATIANA URIEN ORTIZ

De la Corte, L., Blanco, A. y Sabucedo, J. M. (2004). Introducción: Psicología y Derechos Humanos en el siglo XXI. En L. De la Corte, A. Blanco y J. M. Saucedo (Eds.), Psicología y Derechos Humanos (pp. 13-21). Barcelona: Icaria Editorial.

De LoRENzo, R. (2003). El futuro de las personas con discapacidad en el mundo. Madrid: Fundación Once. En http://www.cermi.es/esES/Biblioteca/Lists/Publicaciones/Attachments/5/ FuturoDiscapacidad.pdf.

Dworkin, R. M. (1984). Los Derechos en Serio. Madrid: Ariel.

Dworkin, R. M. (2003). Virtud soberana: La teoría y la práctica de la igualdad. Barcelona: Paidós.

Dworkin, R. M. (2008). La democracia posible. Principios para un nuevo debate político. Barcelona: Paidós.

ERIKSON, E. H. (2000). El ciclo vital completado. Barcelona: Espasa.

Fernández Dols, J. M. (2004). Decoro. Manuscrito no publicado. Facultad de Psicología, UAM. Glover, J. (2001). Humanidad e inhumanidad. Una historia moral del siglo XX. Madrid: Cátedra. LindNER, E. (2006). Making enemies. London: Praeger Security International.

Margalit, A. (1997). La sociedad decente. Barcelona: Espasa Libros.

Mill, S. (1984). Sobre la libertad. Madrid: Alianza.

ONU (1948). Declaración Universal de los Derechos Humanos. Adoptada en Ginebra por la Asamblea General de Naciones Unidas el 10 de diciembre de 1948. En http://www.un.org/ es/documents/udhr/.

ONU (2006). Convención Internacional sobre los Derechos de las Personas con Discapacidad. Adoptada por la Asamblea General de las Naciones Unidas el 13 de diciembre de 2006, durante el sexagésimo primer periodo de sesiones de la Asamblea General, por la Resolución 61/106. En http://www.un.org/spanish/disabilities/.

ONU (2014). Observación General n. ${ }^{\circ} 1$. Adoptada por el Comité Sobre los Derechos de las Personas con Discapacidad del 31 de marzo al 11 de abril de 2014 durante el undécimo periodo de sesiones. En http://www.google.es/url?sa=t\&rct=j\&q=\&esrc=s\&source=web $\& c d=1 \& v e d=0 C C A Q F j A A a h U K E w i W s f W E 7 s n I A h V B 1$ hoKHYhVDQM\&url=http $\% 3$ A\%2F\%2Fwww.ohchr.org\%2FDocuments\%2FHRBodies\%2FCRPD\%2FGC\%2FDG CArticle12_sp.doc\&usg=AFQjCNEEUj2tNWYED-r_EqdGZCMHq49P5g\&sig2=cdd5 MmcUGC2Ekipp1aUQIQ\&bvm=bv.105454873,d.bGg.

Ortega y Gasset, J. (1988). El tema de nuestro tiempo. Madrid: Espasa Calpe.

Palacios, A. (2008). El modelo social de discapacidad: orígenes, caracterización y plasmación en la Convención Internacional sobre los Derechos de las Personas con Discapacidad. Madrid: Ediciones Cinca. En http://www.cermi.es/esES/ColeccionesCermi/Cermi.es/Lists/Coleccion/Attachments/64/Elmodelosocialdediscapacidad.pdf.

Palacios, A. y Bariffi, F. (2007). La discapacidad como una cuestión de derechos humanos. Madrid: Ediciones Cinca.

Palacios, A. y Romeñach, J. (2009). El modelo de la diversidad. Madrid: Ediciones Diversitas. Rawls, J. (1979). Teoría de la Justicia. Madrid: Fondo de Cultura Económica.

Rosales, O. (2012). Discapacidad, Justicia y Estado. Buenos aires: Infojous. En http://www. cermi.es/esES/Agenda/Lists/Eventos/Attachments/180/Libro\%20Acceso\% 20 a $\% 20$ la $\% 20 J u s t i c i a \% 20$ de $\% 20$ lasPersonas $\% 20$ con $\% 20$ Discapacidad.pdf.

Schalock, R. L. y Verdugo, M. Á. (2013). El cambio en las organizaciones de discapacidad. Madrid: Alianza Editorial.

SEN, A. (1997). Bienestar, justicia y mercado. Barcelona: Paidós.

TAMARIT, J. (2010). La educación que queremos: avanzando hacia proyectos singulares de felicidad. En D. ERoles (Ed.), VII Jornadas de Cooperación Educativa con Iberoamérica

(C) Ediciones Universidad de Salamanca / CC BY-NC-ND

Siglo Cero, vol. 47 (2), n. ${ }^{\circ}$ 258, 2016, abril-junio, pp. 43-62

$$
-61-
$$


sobre Educación Especial e Inclusión Educativa (pp. 49-65). Madrid: Oficina de Santiago. En http://unesdoc.unesco.org/images/0021/002140/214053s.pdf.

Tamburrino, C. (2009). Contribución a una crítica epistemológica de la discapacidad intelectual. Feminismo/s, 13. En http://hdl.handle.net/10045/13333.

\section{Financiación y agradecimientos}

Este artículo es una reflexión fruto del trabajo final del Máster Plena inclusiónUAM. Máster que he tenido la oportunidad de realizar gracias a la financiación de Plena inclusión y de la Asociación Uribe Costa, mi casa desde hace tantos años.

También quiero dar las gracias al profesor José Miguel Fernández Dols por guiarme pacientemente en este viaje a través del poder transformador de los conceptos, confiando siempre en mí mucho más que yo. 